\title{
Science of Lagging Behind- Hysteresis in Soil Moisture Characteristic Curve - A Review
}

\author{
Prithwiraj Dey $^{1 *}$, Prerna Sundriyal ${ }^{1}$ and Sanjib Kumar Sahoo ${ }^{2}$ \\ ${ }^{1}$ Department of Agronomy, ${ }^{2}$ Department of Soil Science, G.B. Pant University of Agriculture \\ and Technology, Pantnagar, UK-263145, India \\ *Corresponding author
}

\section{A B S T R A C T}

\begin{tabular}{|l|}
\hline Ke y w o r d s \\
Hysteresis, Soil \\
Moisture Curve, \\
$\begin{array}{l}\text { Desorption, } \\
\text { Capillary hysteresis, } \\
\text { Water retention. }\end{array}$ \\
\hline Article Info \\
\hline $\begin{array}{l}\text { Accepted: } \\
\text { 04 September } 2017 \\
\text { Available Online: } \\
\text { 10 October } 2017\end{array}$ \\
\hline
\end{tabular}

Keywords

Hysteresis, Soil Moisture Curve, Capillary hysteresis, Water retention.

\section{Introduction}

Soil water retention characteristics and release pattern in of utmost importance in agricultural science not only as because it provides moisture to the plants for survival, the soil moisture also has deciding role in the nutrient dynamics, soil physical and chemical properties and on soil microflora. Keeping the importance of soil water and its contribution towards agriculture in mind, the soil moisture related parameters such as soil moisture retention and release pattern, hydraulic conductivity, infiltration rates etc. have been studied extensively so far by several workers. In the study of soil moisture content in relation with particular suction or tension, a discrepancy was reported so far.
It has been found and described by Haines (Haines,1930) that the volumetric moisture content in soil in relation with a particular suction or tension force is different depending upon the soil is wetting or the soil is drying and termed as 'Hysteresis' (Haines, 1930).

\section{Etymology}

The root of the word 'Hysteresis' can be traced in the ancient Greek text. It is believed to be originated from the Greek word'Husteros' meaning 'late'. The word was modified again and again in the course of time to several similar words having similar meanings viz. 'Husterin' meaning 'lag 
behind', 'Husteresis' meaning 'shortcoming or deficiency'. The word was finally accepted in the English language in early 19th century in its current spelling and in the same sense. (Oxford American College Dictionary, 2001)

\section{What is hysteresis?}

Hysteresis is often evident in the field of Physics. Several physical processes have the inherent property of hysteresis. The literal meaning of Hysteresis in scientific term is the history dependency of a system. It means that the hysteresis is a phenomenon that occurs in a system whose current trend can't be predicted without knowing its history.

An example can be given in this regard, at any particular instance, say temperature reading in an air conditioner $25 \mathrm{deg}$. Only this much of information can't tell us whether the temp is falling or rising from the ambient air temp. It can only be said if we have another piece of information that what was the temperature reading at some instances earlier. That is why this type of system depends on its historical state. Let us take another example, say a soil is having $20 \%$ moisture (gravimetric) at a metric suction of 0.33 bar. With this much of information, the trend of soil system as it is drying or it is wetting, can't be decided.

So here lies the importance of the phenomena. Systems that take different pathways for reversing the same process have the characteristics of hysteresis. Haines defined in soil also, sorption or wetting of a dry soil and desorption or drying of a wet soil are two opposite phenomena that follow a different path such that the moisture held in a particular metric suction in sorption process and desorption process are not equal. Generally, the in the desorption process, soil holds moister at a particular metric suction than in the sorption process (Haines, 1930).

\section{Hysteresis in soil moisture characteristics curve}

The curves plotted in relation with matric suction of the soil $\left(\phi_{\mathrm{m}}\right)$ and the volumetric moisture content in soil $\left(\theta_{\mathrm{v}}\right)$ is known as Soil Moisture Characteristics curve or soil moisture characteristic curve. The soil moisture characteristic curve may be also called as Soil moisture retention curve. This type of characteristic curve may be generated by simply plotting the tensiometer reading of $\phi_{\mathrm{m}}$ and volumetric water content on that particular suction. But it also has two methodologies viz, drying a pre wetted soil and wetting a pre dried soil. The soil moisture characteristic curve obtained from e drying soil i.e. moisture content is successively decreasing is called the desorption curve. On the contrary, soil moisture characteristic curve obtained from a wetting soil sample i.e. successively increasing moisture content is called the sorption curve. After Haines, it has been several times experimented and confirmed that the two curves viz. sorption curve and desorption curve do not follow the same reversible path (Haines, 1930).

However that is evident only in case of a midrange of suction force. At higher and at lower ranges the two curves coincides with each other giving rise to a single curve. In such part of the soil moisture characteristic curve, Hysteresis is not a matter of significance as it takes very low even tending to zero value as both curve merges into one (Ebrahimi-birang et al., 2007).

In the figure 1 the two main curves viz. sorption and desorption curves are continuous though out their path. They join each other at higher and lower suction ends. But the curve is that simple in case of monotonic process of wetting with processes like infiltration and drying with evapotranspiration. Dichotomy in the process is evident often in soil condition 
in events like soil moisture redistribution within the profile. Both the process of sorption and desorption may occur simultaneously making the scenario quite difficult to understand.

If the soil is not allowed to be wetted properly in the course of wetting and is made subjected to drying in the midway or vice versa, the soil moisture curve takes some small intermediate path or spurs between the two main curves.

These small curves are known as Scanning Curves or Haines Jumps (Haines, 1930).
These makes the phenomena complicated enough to study. But unfortunately the complicated case is not an imaginary one but very common event in practical and field consideration.

\section{Causes of hysteresis}

Several causes were identified so far and been worked upon by several workers. The main cause that is supposed to contribute more towards hysteresis in a porous media may be attributed to the non-uniformity of the pores (Haines, 1930).

Fig.1 Sorption and desorption curves, scanning curves

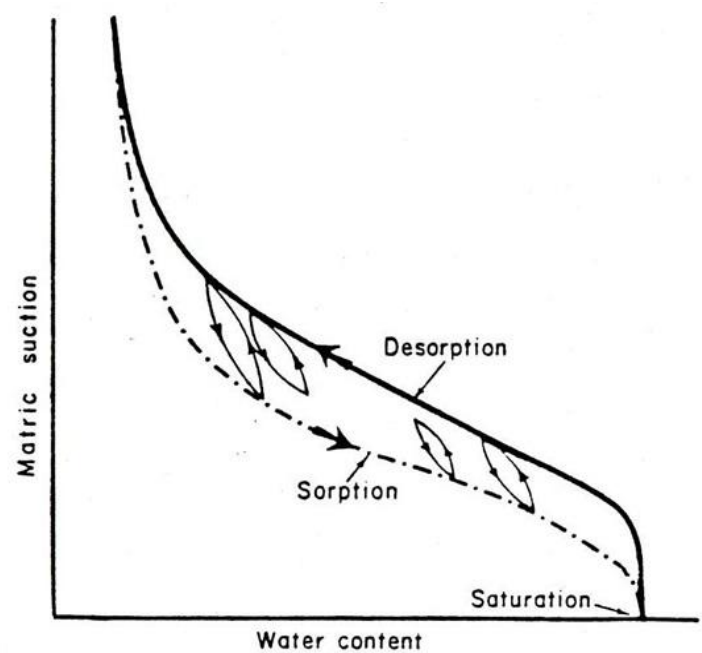

Fig.2 Ink bottle effect

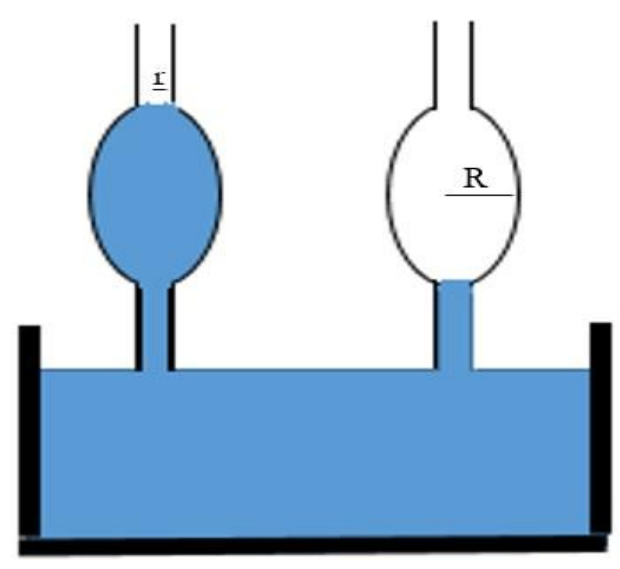


Fig.3 Wetting process and changes in contact angle

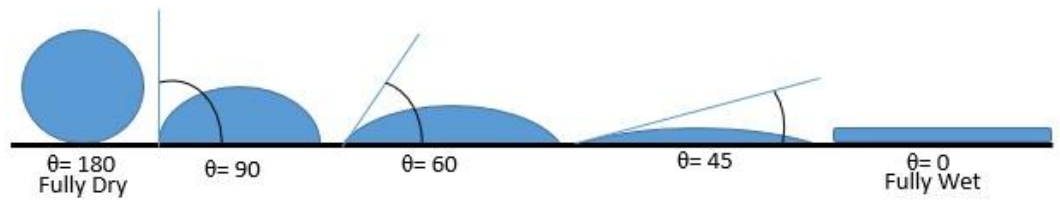

Fig.4 Influence of entrapped air

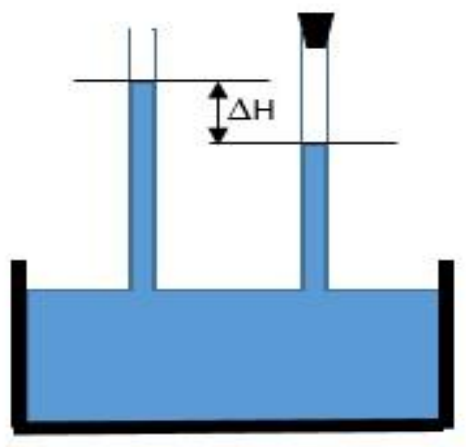

It is obvious, that pores in soil are geometrically heterogeneous as the have different size configurations. Generally the larger pores are connected with very narrow connecting capillary pores. This difference in path diameter leads to deviations in the wetting and the drying path of soil system. From the theory of capillarity, we can conclude that the capillary rise or the capillary holding capacity depends on the radii of the capillary. So, the suction needed to empty a pore or to fill a pore also depends upon the pore radii as the holding forces are dependent upon it.

In the figure 2 of hypothetical pore of radii $r$ in the narrower part of the pore and $\mathrm{R}$ in the relatively wider part of the pore. Then, from the Laplace's equation, it can be said that the pore will abruptly drain at the moment when matric suction $\psi_{\mathrm{r}}$ will just exceed the value $2 \gamma / \mathrm{r}$ where $\gamma$ denotes the surface tension and $\mathrm{r}$ is the pore radii of the smaller part. Value of $\cos \theta$ is considered to be 1 i.e. the value of $\theta$ is taken to be 0 degree as in the top most level of a capillary when capillary rise stops, the meniscus of liquid makes very small contact angle tending to zero due to the achieved equilibrium in the pressure above the meniscus and just below it. For the ease of understanding, the negative sign in original capillary equation is ignored as we are taking matric suction value instead of matric potential. In a similar way for the rewetting of the pore again the suction must decrease from the critical value. But in that case the pore will fill from the lager diameter part and be decided by the larger pore diameter. In that case the matric suction $\psi_{\mathrm{R}}$ should be just less than $2 \gamma / \mathrm{R}$. As we know R $>\mathrm{r}$, it means $\psi_{\mathrm{R}}<\psi_{\mathrm{r}}$ for the same amount of water as volume remains unchanged. Or on the other hand the volume of water retained in soil for a constant suction is less in wetting process than drying (Fig. 3). This is considered as the prime cause of hysteresis in soil moisture characteristic curve. It is popularly known as ink bottle effect as an ink bottle also have smaller radii 
at the neck portion and a larger radii for rest of the shape.

Another cause may be the difference in the contact angle in wetting and drying phases. As shown in the figure contact angle decreases as a surfaces wetted from contact angle $\theta=180$ in fully dry condition to $\theta=0$ in fully wet condition. From the illustration it can also be seen that with the decreasing contact angle, the radius of curvature increases. So the angle of curvature will be greater for the wetting meniscus that the drying one. So from capillarity property, a given amount of water will show greater suction in the desorption curve due to the increasing contact angle. The contact angle difference may also be attributed by the surface characters of the pores, adsorbed irons etc. The contribution of each factor separately is not properly known till date.

Another possible cause may be the entrapped air within the pore after the pore empties. Entrapped air in pores doesn't interfere with desorption process as pores are filled with water and there is no significant amount of air entrapped (Fig. 4). But once the pores drain water, air enters in to the pore. When the pore is subjected to wetting again, the air entrapped creates pressure over the rising water meniscus. As a result, the pores at a particular suction, the emptying pores have more water in comparison to the filling pores.

The pore characteristics of the soil are subjected to change by the soil structure as well as the soil textural influences (Witkowska-Walczak, 2006). Hysteresis phenomena also reported to be attributed by the swelling of the clay in sorption process resulting in pore constriction and reverse in shrinkage (Everett et al., 1966).

It was also been reported by some workers that air dissolved in the soil solution releasing from soil water and re-dissolving to soil water in different pace may also cause hysteresis though this theory is not very popular and not well evident (Hillel, 1980).

\section{Hysteresis models}

Several theories have been proposed to idealize the phenomena and predict the behaviour of hysteretic soil moisture characteristic curves. All the proposed models come under two broad heads viz. Conceptual Models and Empirical Models. Domain theories are the core words of the conceptual models. By this theory we can assign soil moisture to different domains in soil system on the basis of a defined distribution function. On the other hand Empirical models depends on the actually observed data and thus defines and predicts the shape trends of soil moisture characteristic curve. A model which expresses a curve as a function of $n$ number of other curves is termed as 'n-branched' model. Models are also classified based on no of deciding branches viz. single branch models and multiple branch models. Several described conceptual models are- Independent domain theory (Everett et al., 1953), Dependent domain theory and Parlange's Model. Empirical models are- Interpolation Model, Slope Model, Scaling Down model \&linear models. Several workers have compared hysteresis models (Viane et al., 1994) and concluded that best conceptual 2 branch model were Mulaem's modified independent domain models (Mulaem II \& IV) (Mualem, 1973, 1974, 1977, 1984; Poulovassilis, 1961) and in the Parlange's model was found best in the single branch model (Maqsoud et al., 2004).

As the name indicates, hysteresis is truly a phenomenon of lagging behind. It still remains complicated in the field of physics. More complication must be considered when studied under soil condition. Several workers significant contribution towards the phenomena has made it clear to much extend. 
But till now our prediction models are not exact in predicting the behaviour of soil moisture characteristic curve under complex natural wetting drying condition. So, future research scope lies in revising the causes and improving the prediction models to a greater extend (Brooks et al., 1964). We just can't ignore the phenomena only by considering the desorption curve value, we should investigate deep into the evident phenomena for the sake of curiosity and wider understanding. Better understanding of hysteretic character will surely enhance our knowledge about soil moisture retention and drainage and the physical processes inside the soil system.

\section{References}

"Hysteresis": The Oxford American College Dictionary, through Google.com. 2001.

Brooks, R. H. and A. T. Corey. 1964. Hydraulic properties of porous media. Hydrology Paper No. 3. Colorado State University, Fort Collins.

Ebrahimi-birang, N., et al., 2007.Hysteresis of the soil-water characteristic Curve in the high suction range. Ottawageo2007

Everett, D. H., and F. H. Smith. 1953. A general approach to hysteresis - Part 2: Development of the domain theory. Transaction Faraday Society. 50:187197.

Haines, W., 1930. Studies in the physical properties of soil: The hysteresis effect in capillary properties, and the modes of moisture distribution associated therewith. J. Agric. Sci. 20:97-116.

Hillel, D., 1980. Fundamentals of Soil Physics. Academic Press, New York. pp. $155-161 ; 457-464$

Hillel, D., Mottes, J. 1966. Effect of plate impedance, wetting method and aging on soil moisture retention. Soil Sci. 102(2): 135-139

Maqsoud, A., B. Bussière, M. Mbonimpa, and M. Aubertin. 2004. Hysteresis effects on the water retention curve: A comparison between Laboratory results and predictive models. $57^{\text {th }}$ Canadian Geotechnical Conference and $5^{\text {th }}$ Joint CGS/IAH-CNC Conference.

Mualem, Y., 1973. Modified approach to capillary hysteresis based on a similarity hypothesis. Water Resour. Res. 9(5):1324-1331.

Mualem, Y., 1974. A conceptual model of hysteresis. Water Resour. Res. 10(3):514-520.

Mualem, Y., 1977. Extension of the similarity hypothesis used for modeling the soil water characteristics. Water Resour. Res. 13(4):773-780.

Mualem, Y., 1984. A modified dependentdomain theory of hysteresis. Soil Sci. 137(5):283-291.

Poulovassilis, A., 1961. Hysteresis of pore water: an application of the concept of independent domains. Soil Sci. 93:405412.

Viane, P., H. Vereecken, J. Diels, and J. Feyen. 1994. A statistical analysis of six hysteresis models for the moisture characteristics. Soil Sci. 157:345-355.

Witkowska-Walczak, B., 2006. Hysteresis between wetting and drying processes as affected by soil aggregate size. Int. Agrophysics. 20:359365

\section{How to cite this article:}

Prithwiraj Dey, Prerna Sundriyal and Sanjib Kumar Sahoo. 2017. Science of Lagging BehindHysteresis in Soil Moisture Characteristic Curve - A Review. Int.J.Curr.Microbiol.App.Sci. 6(10): 151-156. doi: https://doi.org/10.20546/ijcmas.2017.610.019 